\title{
Using Synthetic Resins for Removal of Emulsified Oil from Produced Water
}

\section{Raafat Alenany, Wisam Alsaba, Mohamed Zamzam, Hania Albatrni, Hazim Qiblawey* and Majeda Khraisheh}

Department of Chemical Engineering, Qatar University

*hazim@qu.edu.qa

\section{Abstract}

In this study, adsorption of emulsified oil in produced water was experimented using synthetic resins. Adsorbent dosage, contact time, initial oil concentration, and $\mathrm{PH}$ were the main key parameters evaluated for Optipore L493, Amberlite IRA 958, Amberlite XAD 7 and Lewatit AF 5. Oil removal rates have reached up to $98 \%$ using AF 5, XAD 7 and L493, while they are lesser than 25\% for IRA 958. Isotherm data were fitted using Langmuir, Freundlich, Toth, Flory Huggins and DubininRadushkevich models. Adsorption isotherms for XAD 7 and L 493 were best fitted using Langmuir model, whereas AF 5 curves were best fitted using DubininRadushkevich. Kinetic data describing the rate of adsorption for each resin were studied and fitted using pseudo-first and second order equations in addition to intraparticle diffusion models. The experimental results were best fitted using pseudo second order kinetics. The obtained results confirm the applicability of the resins for the removal of oil from produced water.

\section{Produced Water and its Management}

It is defined as waste byproduct generated in the exploration and production of oil and gas from onshore or offshore wells. It is also defined as water extracted from underground formations and brought up to the surface along with the oil and gas.

\section{Management of PW}

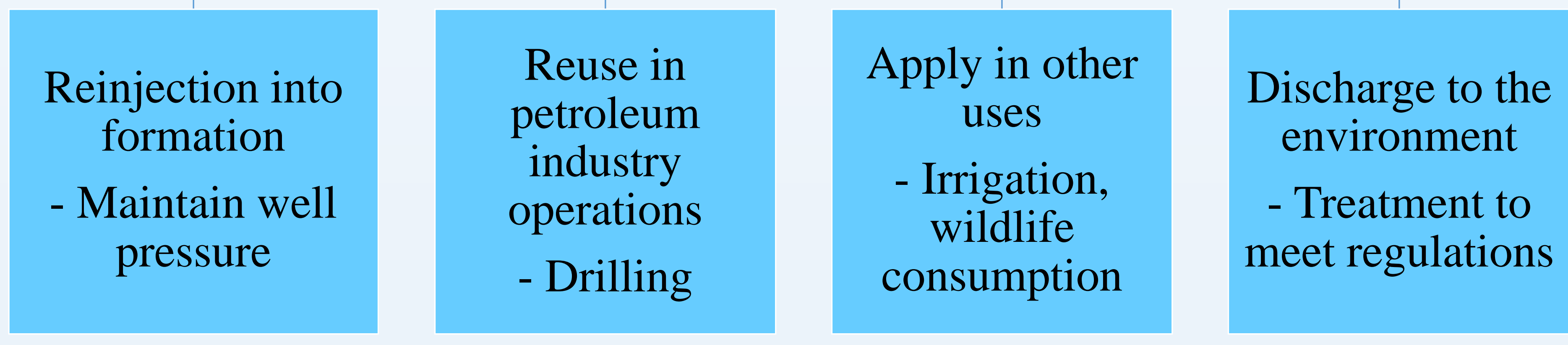

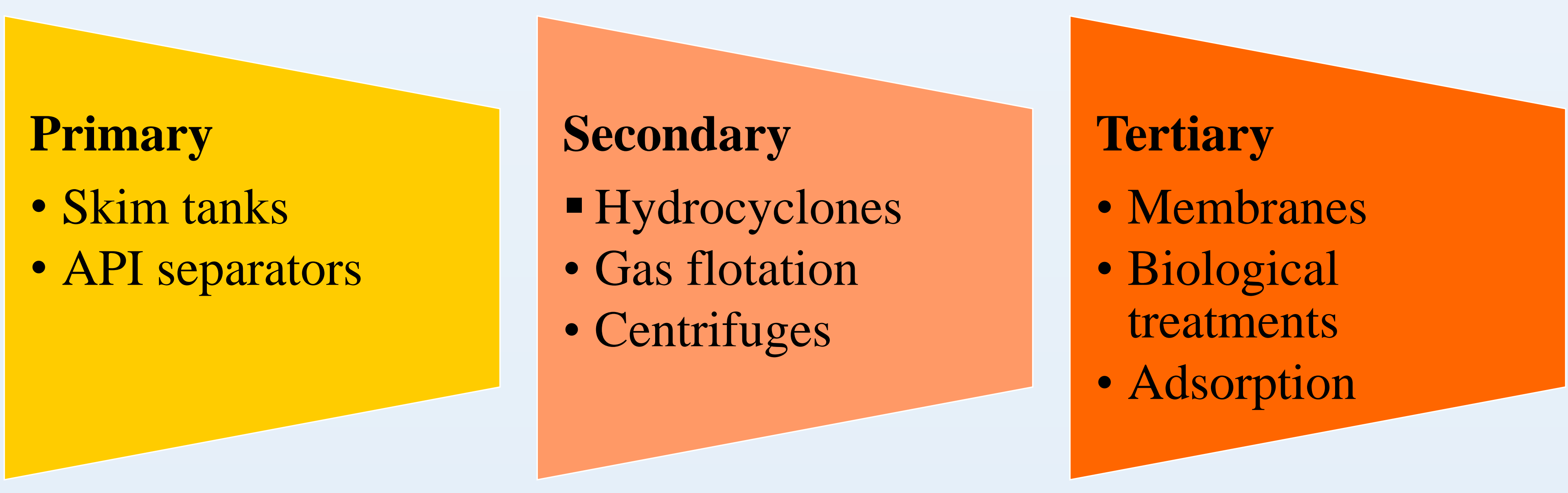

\section{Methodology}

The adsorption potential of the synthetic resins was determined by various parameters. The parameters investigated are: Changing adsorbent dosage, contact time, initial adsorbate concentration and the effect of $\mathrm{pH}$. The experiments were conducted on four different resins. The solution was exposed to resins and placed in glass bottles which were then placed on a mechanical shaker for the mixture to be well agitated. The experiments were considered to be batch experiments and were performed at room temperature and pressure. The $\mathrm{pH}$ was remained constant in the all parameters but the effect of $\mathrm{pH}$ at about 6.7, and the mechanical shaker was set at $180 \mathrm{rpm}$.

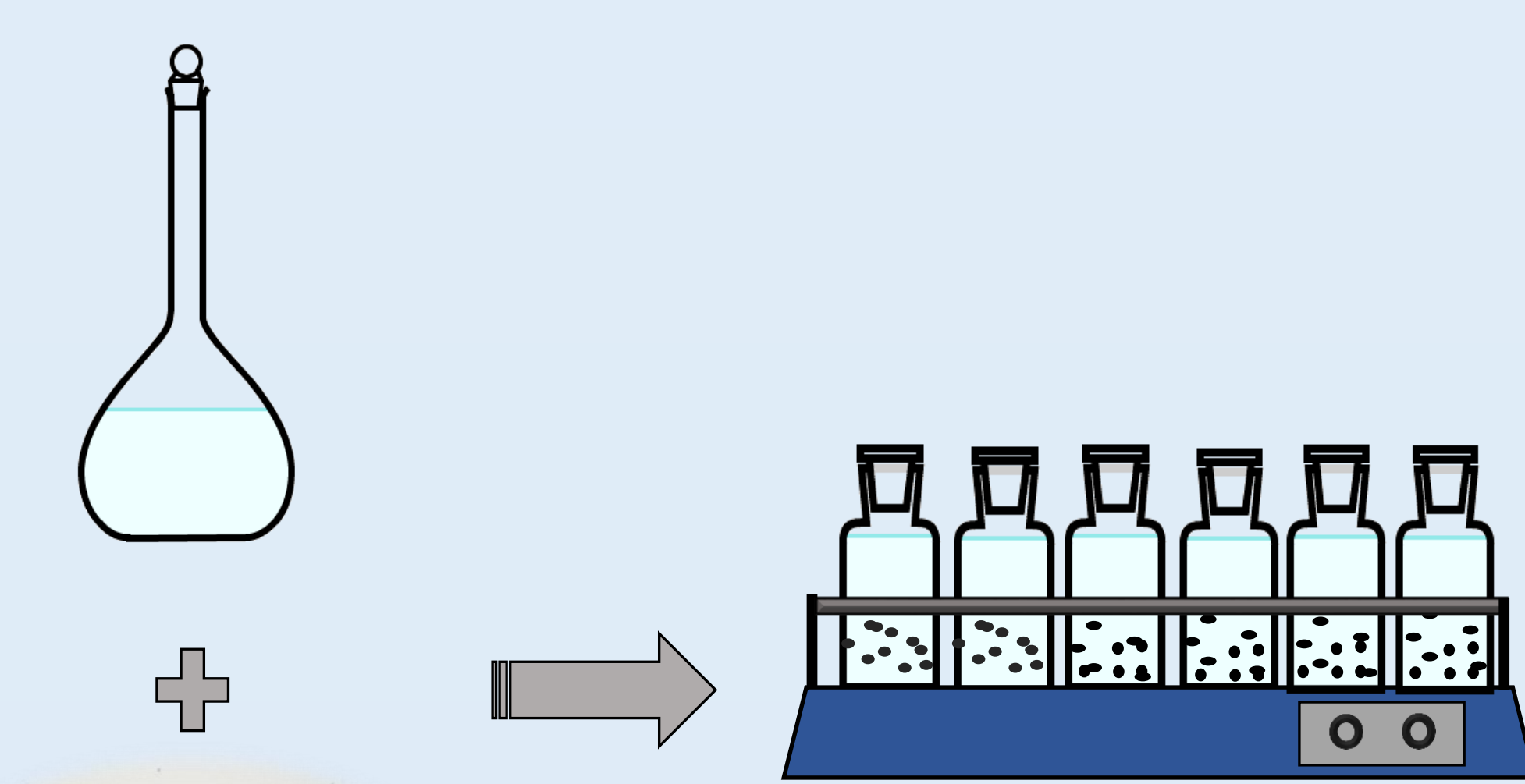

\section{Objectives}

- Manually prepare a close-to-real solution of produced water to simulate the conditions for the tertiary treatment

- Conduct lab scale experiments to investigate the potential of synthetic resins to remove the organic compounds from the produced water

- Anticipate the batch kinetics and adsorption isotherms to evaluate adsorption capacity and efficiency of the synthetic resins

- Conduct regeneration experiments to determine the desorption capacity, reusability and effects on the synthetic resins

\section{Results}

Effect of changing parameters
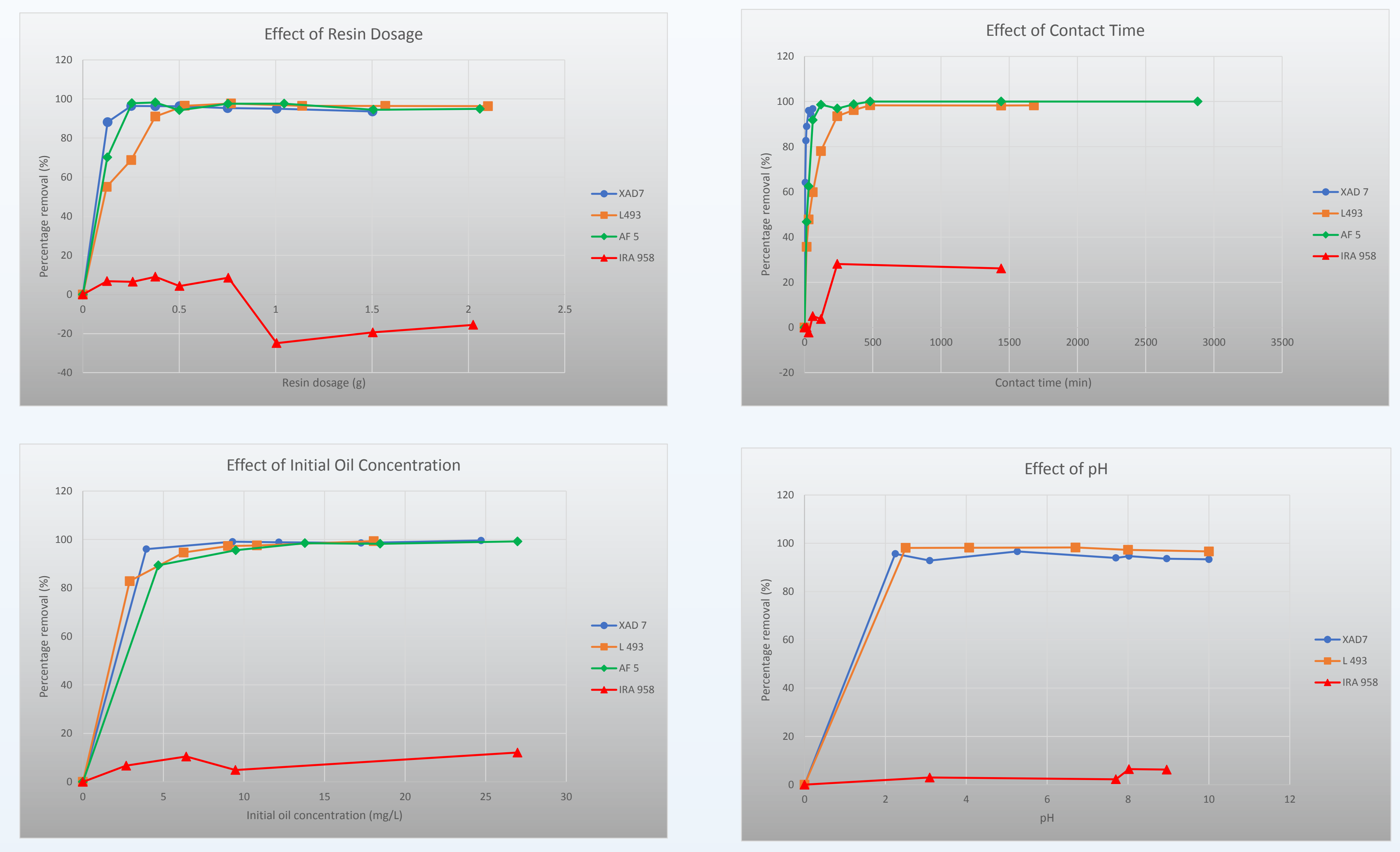

Surface characterization using SEM imaging. (a) AF 5, (b) IRA 958, (c) L493, (d) XAD 7.

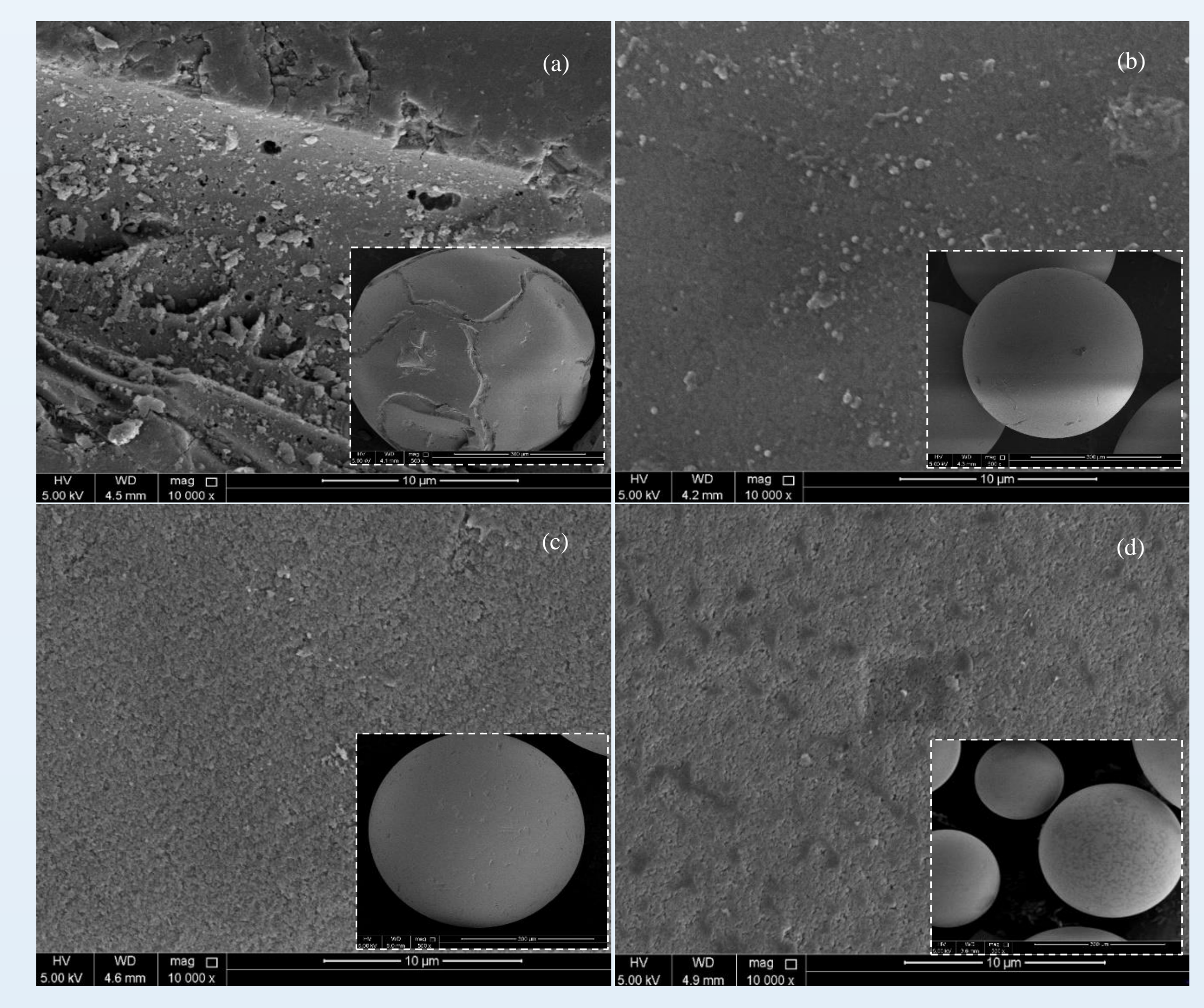

\section{Conclusion}

After conducting the experiments and obtaining the results, XAD 7 and L493 were best fitted to the Langmuir model, AF5 was fitted to Dubinin-Radushkevich model and the IRA 958 was not fitted to any of these models. Moreover, the adsorption kinetics seemed to follow a pseudo-second order trend, which perfectly described the kinetics. The results shows the feasibility of using these resins in adsorbents processes.

\section{Acknowledgement}

This work was made possible by a UREP award [UREP23-041-2-019] from the Qatar National Research Fund (a member of The Qatar Foundation). The statements made herein are solely the responsibility of the author[s].We would like also to specially thank the Central Laboratory Unit (CLU) and the Gas Processing Center (GPC) at Qatar University for their extreme support while performing the adsorption experiments and analyzing the results. 